\title{
Colorectal Cancer in Uganda: A I0-Year, Facility-Based, Retrospective Study
}

\author{
Godfrey Wekha (D) \\ Nelson Ssewante (1) \\ Angelique Iradukunda' \\ Micheal Jurua' \\ Shadia Nalwoga' \\ Sharon Lanyero' \\ Ronald Olum (iD) \\ Felix Bongomin (ID) ${ }^{2,3}$ \\ 'School of Medicine, College of Health \\ Sciences, Makerere University, Kampala, \\ Uganda; ${ }^{2}$ Department of Medical \\ Microbiology and Immunology, Faculty of \\ Medicine, Gulu University, Gulu, Uganda; \\ ${ }^{3}$ Department of Medicine, School of \\ Medicine, College of Health Sciences, \\ Makerere University, Kampala, Uganda
}

Correspondence: Godfrey Wekha School of Medicine, College of Health Sciences, Makerere University, Kampala, Uganda

Tel +256787858218

Email wekha76@gmail.com
Introduction: Colorectal cancer (CRC) is the most common type of gastrointestinal malignancies and the third leading cause of cancer-related deaths for both sexes worldwide. Although the burden of CRC is highest in developed countries, reports are indicating a rise in the incidence of early-onset CRC in developing countries. In this study, we aimed to determine the prevalence of CRC among patients hospitalized with lower gastrointestinal complaints at a tertiary health facility in Uganda.

Methods: We conducted a 10-year retrospective chart review of patients admitted to Mulago National Referral Hospital in Kampala, Uganda, between 1st January 2010 and 31st December 2020. We reviewed all charts of patients admitted to the lower gastrointestinal tract (GIT) ward. Charts with grossly missing data, pediatric patients, and those from other non-lower GIT specialties were excluded.

Results: Data of 1476 unique eligible patients were analyzed. Of these, 138 had a diagnosis of CRC (prevalence: 9.3\%, 95\% confidence interval (95\% CI): 6.5-11.7\%). Among patients with $\mathrm{CRC}$, the female:male ratio was $1: 1$. The most common site for $\mathrm{CRC}$ was the rectum $(59.8 \%, \mathrm{n}=79)$. For the 138 participants with CRC, 44 had staging data with $72.8 \%(\mathrm{n}=32)$ having advanced disease, that is, stage 3 or 4 . Factors independently associated with CRC were age $\geq 50$ years (adjusted odds ratio (aOR): 4.3, 95\% CI: 2.6-7.1, p $<0.001$ ), female sex (aOR: $1.8,95 \% \mathrm{CI}: 1.2-2.8, \mathrm{p}=0.005)$, being widowed (aOR: $2.5,95 \% \mathrm{CI}: 1.3-5.0, \mathrm{p}=$ 0.006), and presence of any risk factor for CRC (aOR: 5.3, 95\% CI: 2.9-9.9, p < 0.001).

Conclusion: $\mathrm{CRC}$ is relatively common among patients hospitalized with lower GIT complaints, particularly among women and those with known risk factors for CRC. Awareness creation and screening programs should be instituted to allow early diagnosis of CRC in our setting.

Keywords: colon, rectum, colorectal cancer, GIT malignancy

\section{Introduction}

Colorectal cancer (CRC) is one of the most common malignancies worldwide, third in men and second in women in terms of incidence, and the third leading cause of cancer-related deaths in both sexes. ${ }^{1}$ Globally, an estimated 10 million deaths occurred in 2020 due to cancers with CRC accounting for $9.4 \%$ of these deaths. ${ }^{2}$ In low- and middle-income countries (LMICs), it accounts for over 600,000 deaths annually, but data concerning cancer rates in these countries are generally very poor. $^{3}$

$\mathrm{CRC}$ is currently considered to be one of the clearest markers of epidemiological and dietary change. ${ }^{4}$ The rise in the global burden is not uniform with significant variations influenced by geographic location, socio-economic status, age, 
and gender. Although high-income countries currently bear the heaviest burden, increasing civilization and dietary changes in LMICs, predict a threatening rise in the incidence rate of CRC. ${ }^{5}$ Indeed, the mortality rate due to rectum and colon cancers in LMICs is projected to rise by up to $60 \%$ and $71.5 \%$ respectively by $2035 .{ }^{5}$ Recent studies have underpinned a high body mass index (BMI), old age, family history of cancer, smoking, and frequent alcohol intake as risk factors for the development of $\mathrm{CRC}^{6,7}$ as do occupational exposures and physical inactivity. ${ }^{6,8-11}$

Over the past two decades, focused research to elucidate the genetic defects and molecular abnormalities associated with colorectal adenomas and carcinomas has been conducted to upscale screening programs. ${ }^{12-15}$ This has yielded promising results with many $\mathrm{CRC}$ cases now diagnosed before the onset of symptoms, especially in highincome countries. Knowledge of the pathobiology and risk factors has also proved useful in the identification of highrisk individuals an important aspect of CRC prevention programs. ${ }^{16,17}$ Unfortunately, in many LMICs including Uganda, few studies have been conducted to gather this information, and screening programs are yet to be conceptualized. Patients usually present with advanced disease with altered bowel habits, weight loss, anemia, abdominal discomfort, and rectal bleeding or diarrhea which predict a poor prognosis. ${ }^{3}$

While communicable diseases are still the major cause of death in Uganda, non-communicable diseases (NCDs) including $\mathrm{CRC}$ are on a rise. With the reported increase in the trend of CRC among young adults and adolescents in other parts of the world, ${ }^{18-20}$ Uganda needs to be equally concerned. Therefore, this study was conducted to provide a baseline trend of CRC in Uganda and shed light on the socio-demographic characteristics of those at risk so that interventions to reduce population risk and individual susceptibility can be formulated.

\section{Methods}

\section{Study Design and Site}

We conducted a retrospective chart review (RCR) at Mulago National Referral Hospital (MNRH) records Department from May to July 2021. Mulago is the main national referral hospital located in Kampala, Uganda. Before 2014, it was operating as a single unit serving Kampala metropolitan area, Wakiso and Mukono, and referrals from all the Regional Referral Hospitals. In 2014, Obstetrics and Gynecology department was relocated to now Kawempe National Referral Hospital, and the Department of Medicine was relocated to now Kiruddu National Referral Hospital with MNRH retaining Surgery and Pediatrics.

\section{Study Population and Selection Criteria}

Charts of all patients who were admitted to the lower gastrointestinal tract (GIT) ward from 1st January 2010 to 31 st December 2020 were retrieved from archives and subjected to a rigorous selection and review process. Charts of pediatric patients, Specialties other than nonlower GIT specialties (ie, urology, orthopedics, and neurosurgery), and those with grossly missing data including sex, age, residence, marital status, occupation, and diagnosis were excluded.

\section{Sampling Procedure}

At MNRH, a paper-based record management system is still in practice. Patients' charts are assigned the archive's code based on their in-patient admission number. The latter is assigned on admission and therefore is based on the year of admission rather than the department where the patient is treated from. Since there's no electronic database in place to trace all admitted patients, charts were manually retrieved from the archives. All files archived within the study period were reviewed.

\section{Data Collection}

Charts that met the selection criteria were isolated and information extracted using an electronic questionnaire designed with the Epicollect5 system. Sociodemographic data included age, sex, residence, marital status, religion, education level, occupation, and risk assessment including alcohol consumption, smoking, diet, and family history of malignancies and familial adenomatous polyposis (FAP) syndrome. However, due to missing data, some of these variables were dropped during pre-testing.

\section{Data Management and Analysis}

Completed questionnaires were downloaded from Epicollect5 and imported to Microsoft Excel 2016 for cleaning and coding. Cleaned data was exported to STATA V15 for analysis. Numerical data were summarized as means and standard deviations or median and interquartile range (IQR) as appropriate. Categorical data were summarized as frequencies and proportions. Associations between independent and dependent variables were assessed using chi-square or Fisher's exact tests for categorical data and independent 
sample $t$-test or Mann-Whitney $U$-tests for numerical data. A $p<0.05$ was considered statistically significant.

\section{Ethical Considerations}

The study was approved by Mulago Hospital Research and Ethics Committee (MHREC) under reference number MHREC: 2031. We chose MHREC instead of Makerere University School of Medicine Research and Ethics Committee corresponding to our affiliation because Makerere University College of Health sciences (MakCHS) uses MNRH as its teaching hospital and because the study was going to be conducted at MNRH. MHREC provided a waiver of consent since our study involved data collected from routine care. However, patients' identifiers like names and inpatient numbers were excluded to ensure anonymity. This study was conducted in accordance with the principles outlined in the Declaration of Helsinki.

\section{Results}

\section{Patient Demographic Characteristics}

A total of 2252 patient charts were reviewed. Of these, 776 were excluded due to grossly missing data, and those belonging to other specialties; Figure 1. Finally, data of 1476 unique patients was analyzed.

Of the $1,476,979(66.3 \%)$ were male and the overall median age was 38 (IQR: 13-92) years as shown in Figure 2. Majority, 1196 (81.6\%) were from urban areas mainly from Kampala. Figure 3 shows the distribution of
CRC cases across all districts in Uganda. Other characteristics are as summarized in Table 1.

Seventy-five $(5.1 \%)$ participants had risk factors for CRC recorded. This included alcohol consumption, smoking, diet on red meat, HIV, and family history of malignancies as shown in Figure 4.

\section{Prevalence of CRC}

The period prevalence of CRC was found to be $9.3 \%$. The lowest prevalence, $5.5 \%$ (4/73) was recorded in 2015 while the highest, $18.8 \%$ (21/112) was recorded in 2019. The trend of CRC cases in relation to the charts reviewed from 2010 to 2020 is represented in Figure 5.

\section{Factors Associated with CRC}

At bivariate analysis, age $(p<0.001)$, sex $(p<0.001)$, marital status $(p<0.001)$, residence $(p=0.002)$, and presence of any risk factor for CRC $(p<0.001)$ were significantly associated with a diagnosis of CRC as indicated in Table 1.

However, in the multivariate analysis, Table 2 , residence was found not to be statistically significant $(\mathrm{p}=$ 0.603). However, age, sex, marital status, and the presence of any risk factor for CRC including alcohol, smoking, HIV, family history of malignancy, and diet maintained statistical significance. The odds of having CRC was 4.3-fold higher in participants aged 50 years and above compared to those younger than 50 years (aOR: 4.3, 95\% CI: $1.2-7.1, \mathrm{p}<0.001)$. Female were found to have 1.8-fold higher odds of developing CRC compared to

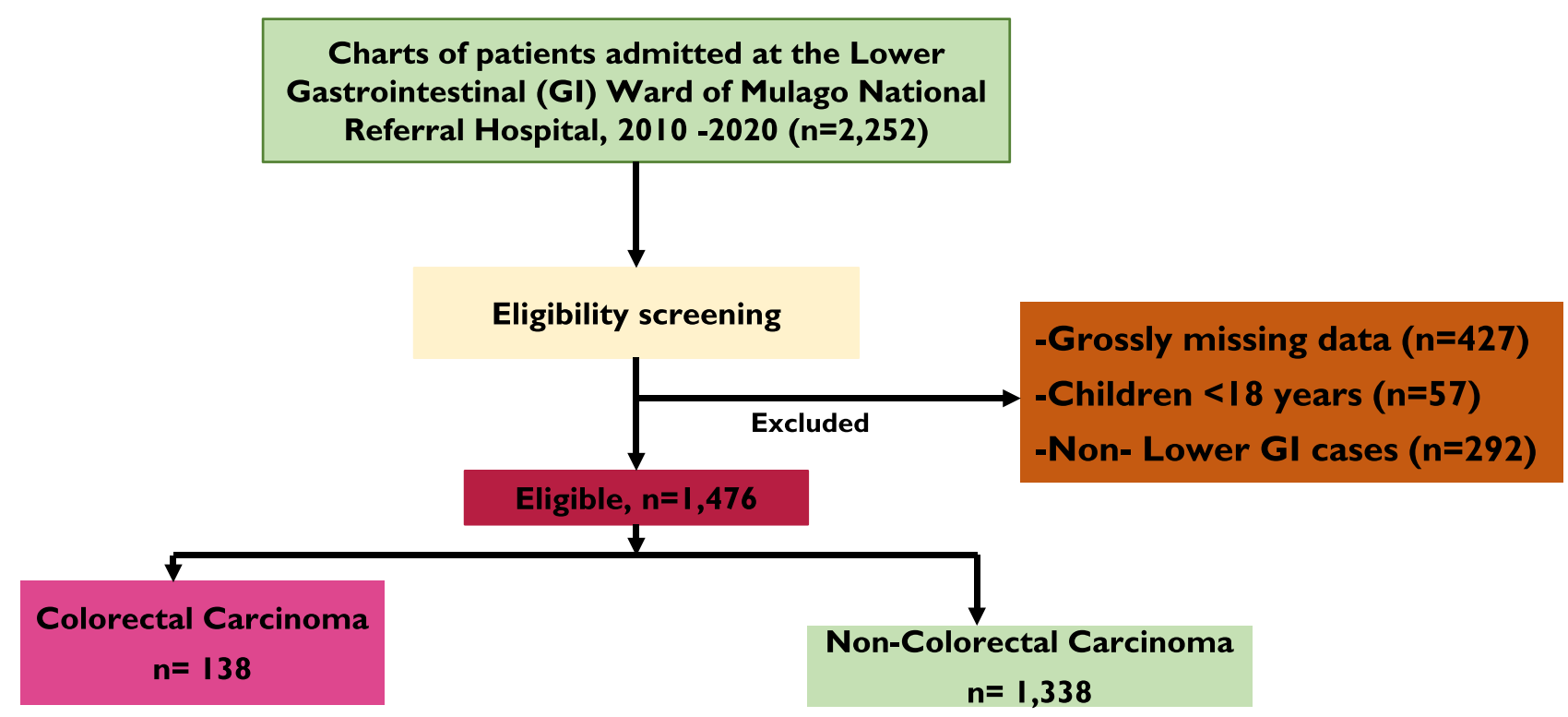

Figure I Study flow diagram. 


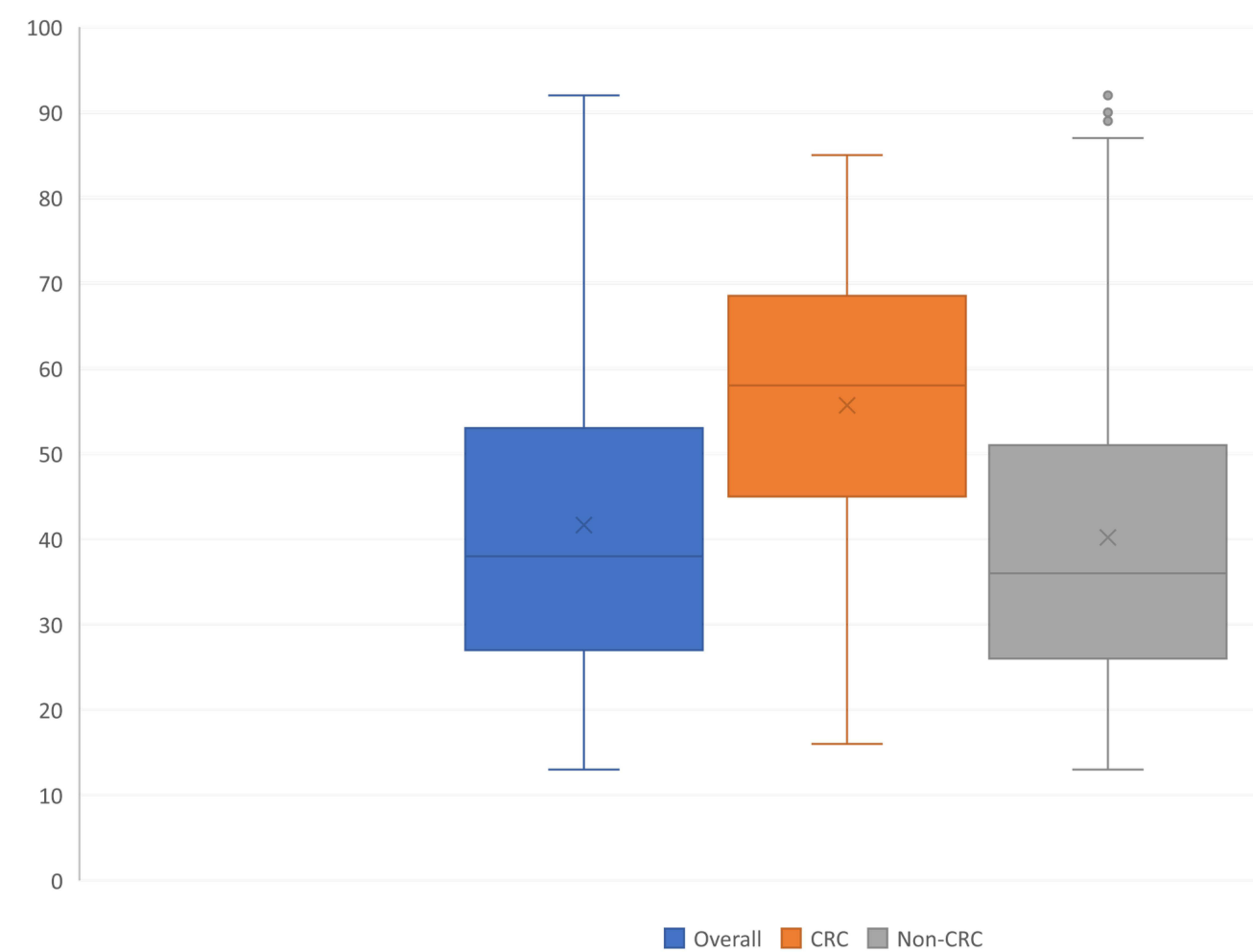

Figure 2 Comparison of median age between CRC and Non-CRC patients.

men (aOR: 1.8, 95\% CI: 1.2-2.8, p < 0.001). Patients who were widowed had 2.5-fold higher odds of having CRC compared to their married counterparts (aOR: $2.5,95 \% \mathrm{CI}$ : $1.3-5.0, \mathrm{p}=0.006$ ) while those identified to have at least one risk factor for CRC had a 5.3-fold higher odds of having CRC compared to those who had none (aOR: 5.3, 95\% CI: 2.9-9.9, $\mathrm{p}<0.001)$.

\section{Clinical Characteristics of CRC at MNRH}

Table 3 summarizes clinical features of the CRC cases recorded in the years 2010 to 2020 .

\section{Discussion}

$\mathrm{CRC}$ is a major public health problem whose etiopathology is not well understood. Globally, CRC is reported to be on the rise with new cases occurring in LMICs where infections have traditionally been a major concern. CRC is the third most common cancer in both males and females worldwide with an estimated 1.9 million new cases in 2020 alone. ${ }^{1,21}$ It is also the second most prevalent cancer and the second leading cause of cancer deaths. ${ }^{1}$ Recent reports predict that the global cancer burden will reach 28.4 million cases by 2040 , with most cases (64-95\%) occurring in developing countries. ${ }^{1}$ Risk factors for this disproportionately high burden are partly due to the aging population and partly to the rapid globalization and the adoption of the associated risk factors within these populations. $^{7,22,23}$ Because of the lack of priority-setting systems in these countries, an epidemic of communicable and non-communicable diseases is likely to emerge. ${ }^{24,25}$

In this study, we found a high prevalence of CRC at 9.3\% across all age groups among patients admitted to the lower GIT ward of MNRH Kampala. This is rather a higher disease burden compared to that previously reported by Bukirwa et al where the disease incidence was found at $4.1 \%{ }^{26}$ This difference in the statistics could be explained by the lack of nationwide screening programs and diagnostic capacities in regional referral hospitals. However, this seems to be a general problem for all LMICs where gaps in detection potentials are reflected in low incidences of CRCs and other cancers. A recent report from GLOBOCAN shows that much as there's a global increase in CRC cases, Africa still has the lowest prevalence accounting for only 3.4\% of the total 1.93 Million new cases regardless of it being the second most populated continent. ${ }^{1}$

Our study showed that age, sex, marital status, and presence of at least one known risk factor for CRC were 


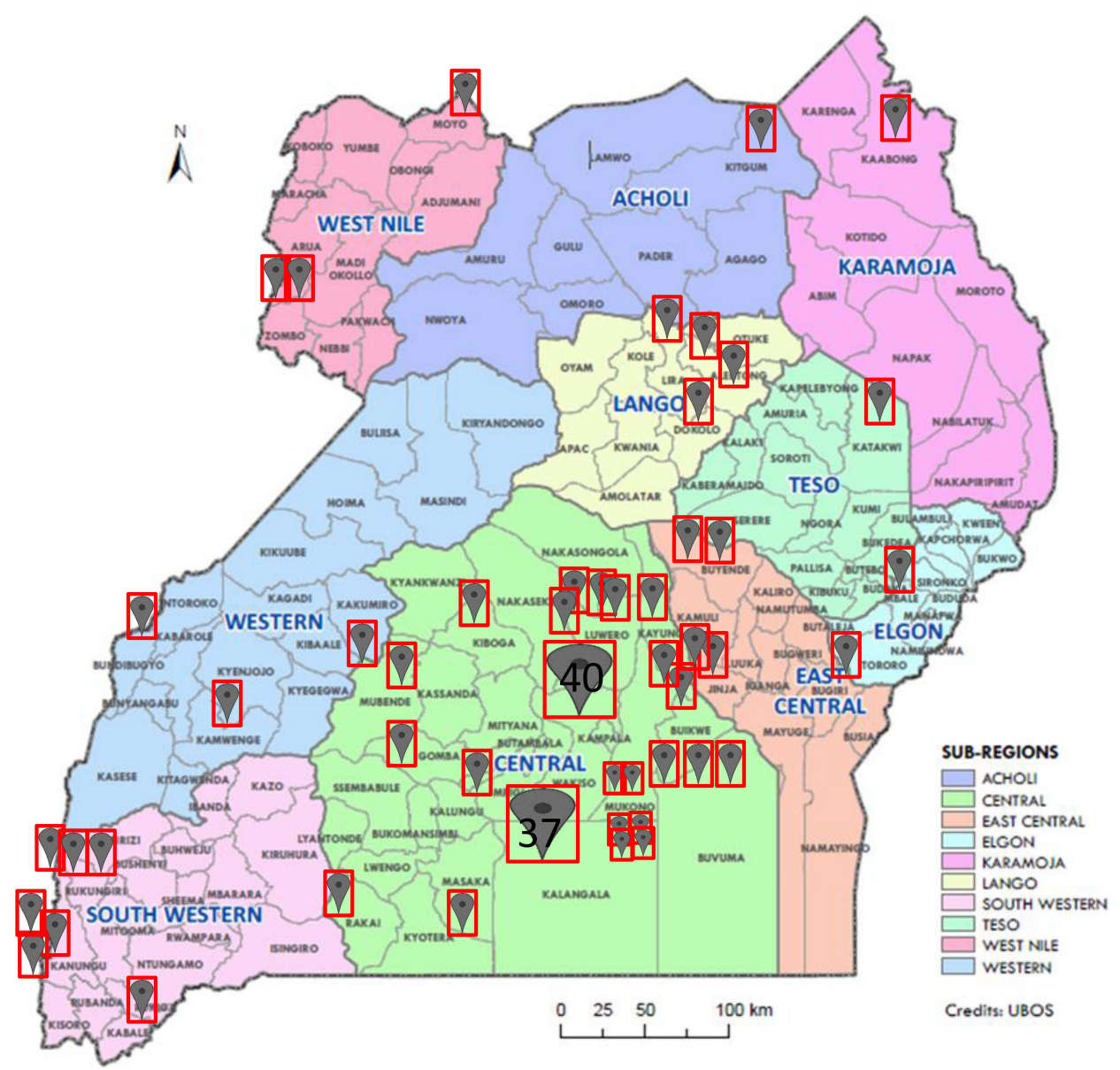

Figure 3 Map of Uganda showing distribution of CRC cases.

strongly associated with CRC. In this study, the likelihood of having CRC was increasing with advancing age, and people above 50 years were at an increased risk. This is in agreement with most literature that conventionally identifies advanced age as a risk factor for CRC. ${ }^{27-29}$ However, up to $30.4 \%$ of CRC cases in this study were diagnosed before 50 years of age. Similar findings were noted in studies conducted in the US, Kenya, Eritrea, and Zambia. ${ }^{30-33}$ What's noteworthy is the fact that these patients present with advanced disease and factors that drive this rapid progression are yet to be understood. Patients in this age group had no history of alcohol consumption, cigarette smoking, comorbidity, or family history of cancer. Indeed, recent reports have also noted rising cases of CRC among adolescents and young adults (AYAs) ${ }^{34-37}$ and the most commonly involved sites were the distal colon and rectum. ${ }^{35,38}$ Unfortunately, the factors influencing this rise are yet to be determined. Genetic predisposition in the face of increasingly sedentary lifestyles as evidence by a steep rise in other NCDs is a possible explanation. ${ }^{28,32}$ Therefore, urgent research is needed to demonstrate the role of screening, illustrate the pathobiology of the disease in these age groups, and explore treatment options for optimal care.

Contrary to current knowledge, ${ }^{28,29}$ females were found to have a greater risk of developing CRC compared to their male counterparts in the current study. Better health-seeking behaviors exhibited by females in Uganda could explain this finding. ${ }^{39}$ Related studies have used difference in life expectancy among males and females as an explanation for gender disparity. ${ }^{40,41}$

Remarkably, marital status was found to be associated with CRC in our study. Widowed patients were 2.5 times more likely to have CRC compared to married patients. To the best of our knowledge, there was no literature supporting this finding. However, this could be explained by the fact that widowed patients do not have regulatory attempts of spouses to monitor their health and promote healthy 
Table I Patient Socio-Demographic Characteristics

\begin{tabular}{|c|c|c|c|c|}
\hline Variables & All & CRC: n (\%) & Non-CRC: n (\%) & \multirow[t]{2}{*}{ p-value } \\
\hline Overall & 1476 & $138(9.3)$ & 1338(90.7) & \\
\hline Age; median (range) & 38 (IQR:I3-92) & 58(IQR:16-85) & 36(IQR: I3-87) & $<0.001$ \\
\hline Age groups & & & & $<0.001$ \\
\hline$<50$ & $1000(67.8)$ & $42(4.2)$ & $958(95.8)$ & \\
\hline$\geq 50$ & $476(32.2)$ & $96(20.2)$ & $380(79.8)$ & \\
\hline Sex & & & & $<0.001$ \\
\hline Female & 497(33.7) & $70(14.1)$ & $427(85.9)$ & \\
\hline Male & $979(66.3)$ & $68(6.9)$ & $911(93.1)$ & \\
\hline Tribes & & & & 0.573 \\
\hline Bantu & $1220(82.7)$ & $112(9.2)$ & $1108(90.8)$ & \\
\hline Nilotes & $176(11.9)$ & $20(11.4)$ & $156(88.6)$ & \\
\hline Others & $80(5.4)$ & $6(7.5)$ & $74(92.5)$ & \\
\hline Residence $(n=\mid 466)$ & & & & 0.002 \\
\hline Rural & $270(18.4)$ & $39(14.4)$ & $23 I(85.6)$ & \\
\hline Urban & $1196(81.6)$ & $98(8.2)$ & I098(9I.8) & \\
\hline Marital status $(n=1219)$ & & & & $<0.001$ \\
\hline Married & $728(59.7)$ & $77(10.6)$ & $65 I(89.4)$ & \\
\hline Separated & $20(1.6)$ & $2(10)$ & $18(90)$ & \\
\hline Single & $420(34.5)$ & $17(4)$ & $403(96)$ & \\
\hline Widowed & $5 I(4.2)$ & $20(39.2)$ & $3 I(60.8)$ & \\
\hline Occupation $(n=405)$ & & & & 0.243 \\
\hline Skilled & $92(22.7)$ & $6(6.5)$ & $86(93.5)$ & \\
\hline Unemployed & $10(2.5)$ & $2(20)$ & $8(80)$ & \\
\hline Unskilled & $303(74.8)$ & $29(9.6)$ & $274(90.4)$ & \\
\hline Risk factors & & & & $<0.001$ \\
\hline No & $|40|(94.9)$ & $1 \mid 4(8.1)$ & $1287(9 \mid .9)$ & \\
\hline Yes & $75(5.1)$ & $24(32)$ & $5 I(68)$ & \\
\hline
\end{tabular}

behavior. And because they do not have anyone to feel responsible towards or get emotional support, they are less likely to engage in healthy lifestyle behaviors. ${ }^{42,43}$

Risk factors for CRC assessed in this study included alcohol consumption, smoking, low fiber and high animal protein diet, family history of malignancies, HIV, and FAP. As expected, patients who had any of these risk factors were more likely to have been diagnosed with CRC. In the study, only $5.1 \%$ of the charts reviewed had documented risks for CRC. However, there was no quantification of the amount of alcohol consumed or pack-years for those who smoked. To date, documentation is still a problem, especially in developing countries. As a consequence, this leads to inaccurate statistical data, poor patients care, and financial losses, ${ }^{44}$ and missed opportunities for those with hereditary predisposition who would otherwise benefit from prevention measures. This finding correlates with that of a study conducted by Abernethy et al, where only 64 of 499 charts of eligible CRC patients were included in the final analysis because of missing data. ${ }^{45}$

The role of diet in the development of CRC has been studied in depth. Most recent studies implicate a diet high in fat, especially saturated fatty acids, red meat, and low in fiber, vitamin $\mathrm{D}$, or dairy products. ${ }^{46}$ The risk of development of CRC due to a high-fat diet is thought to be due to exposure of gut mucosa to carcinogenic heterocyclic amines, polycyclic aromatic hydrocarbons, ${ }^{47}$ and nitroso compounds. ${ }^{48,49}$ Unlike the current study that did not find a strong relationship between diet and CRC, two previous studies demonstrated a significant relationship between plasma phospholipids and CRC. $^{50,51}$ As previously mentioned, poor documentation could have contributed to this negative finding. 


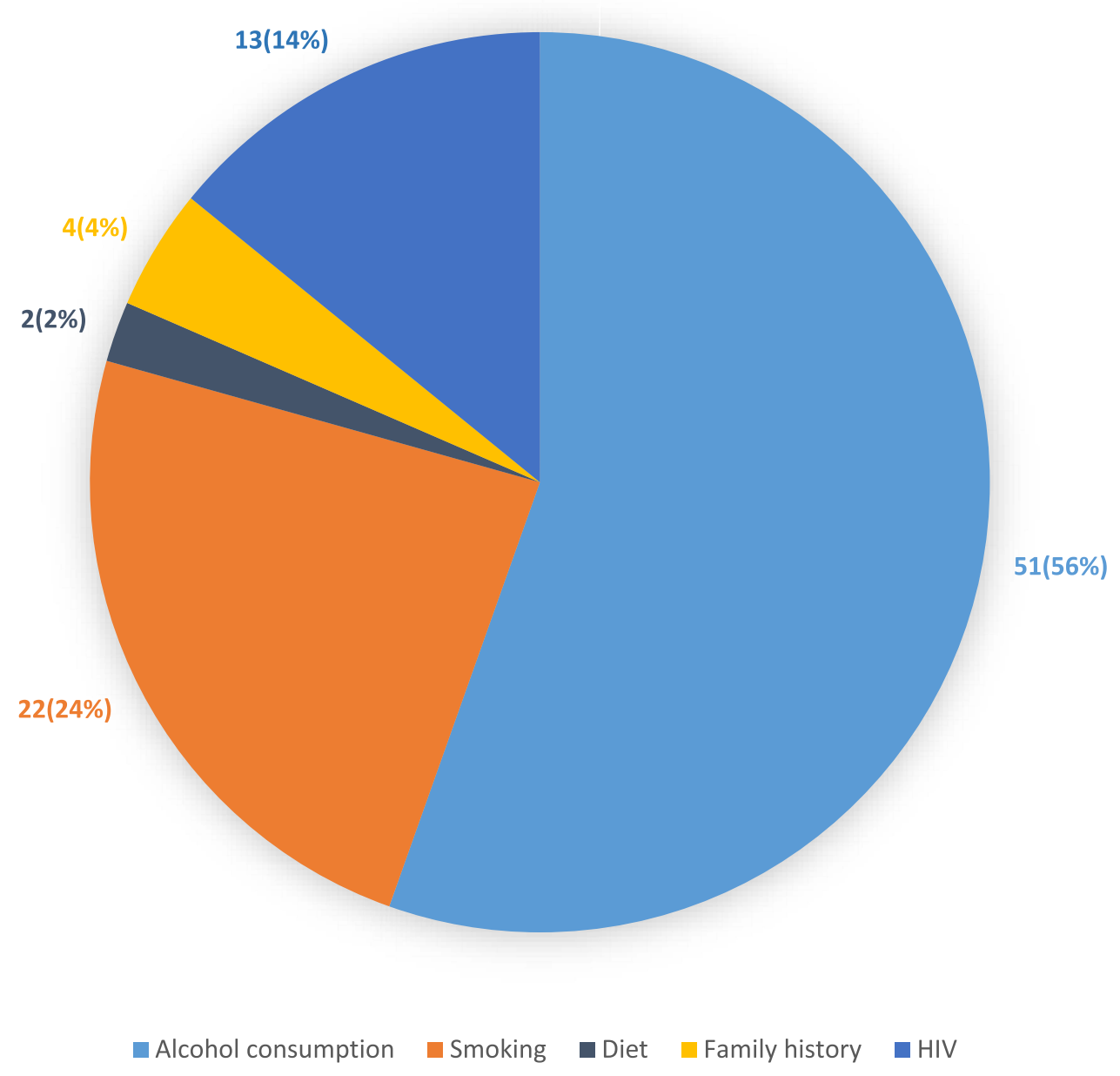

Figure 4 Risk factors associated with CRC.

Over the past decade, CRC has been on the rise globally with an overall incidence of 29 per 100,000 in men and 20 per 100,000 in women. ${ }^{1}$ In this study, however, there seemed to be two peaks between 2010 and 2012 and 2018 and 2020, respectively. Age-adjusted statistics also follow the same trend with all age groups affected equally. Consistent with previous reports, we found no statistically significant difference in tumor location in both sexes. ${ }^{52}$ However, the most common sites were the rectum and cecum with most patients $(72.8 \%)$ having advanced disease which is in agreement with a study conducted in Zambia and South Africa. ${ }^{33}$ This finding could be a result of poor health service-seeking behavior in the general population, lack of risk stratification models for $\mathrm{CRC}$, and the fact that the disease is asymptomatic until its advanced stage.

$\mathrm{CRC}$ is a heterogeneous disease at the molecular and genetic levels. The vast majority of cases result from polyps (slow-growing precursors) that can easily be cured by simple resection. Widely accepted mechanisms of development of CRC include the Chromosomal instability (CIN) pathway accounting for more than $80 \%$ of cases, ${ }^{53} \mathrm{CpG}$ island methylation phenotype (CIMP) that leads to the development of sporadic $\mathrm{CRC},{ }^{54}$ and the pure microsatellite instability pathway.

Our study is the first empirical study in Uganda to attempt to determine the prevalence and factors associated with CRC. However, the results of this research should be construed with caution due to some limitations. Firstly, some of the patients' charts had a great deal of missing data hence they were excluded from the study and secondly, the filing system at the records office entailed the use of admission numbers as opposed to the specialty or ward of admission thus fewer patients' charts were reviewed in comparison to that in the sample size. Secondly, the catchment area of the study site is limited to majorly central Uganda and thus findings may not be generalizable to the entire country. 


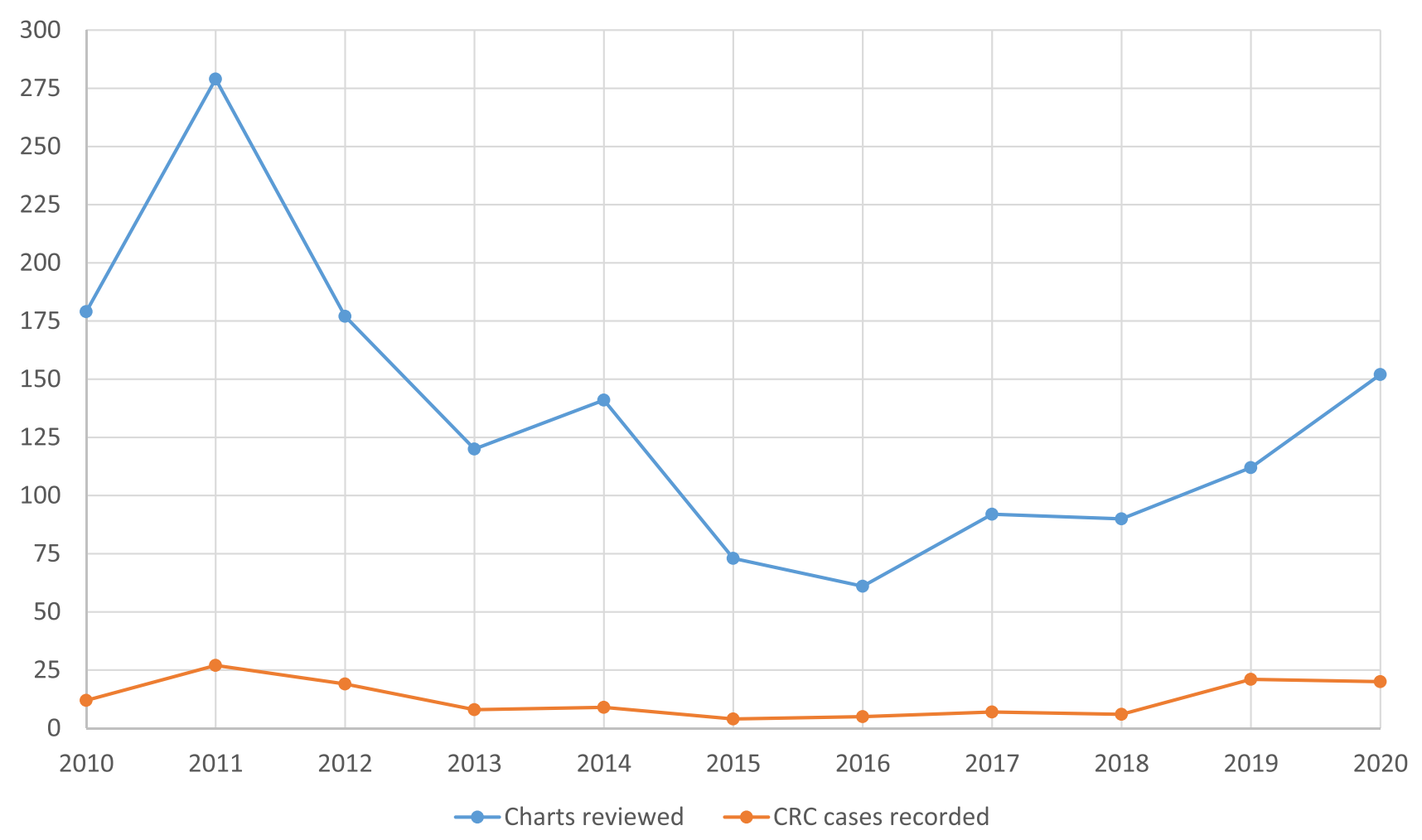

Figure 5 The trend of CRC cases recorded from 2010 to 2020.

Future prospective cohort studies could be con- to screen patients with identifiable risk factors for ducted to identify the population at risk and $\mathrm{CRC}$ so that appropriate interventions are performed incidence of CRC. Particularly, clinicians should seek timely.

Table 2 Multivariate Logistic Regression of Factors Associated with Colorectal Cancer

\begin{tabular}{|c|c|c|c|}
\hline Variables & Adjusted Odds Ratio & p-value & 95\% Confidence Interval \\
\hline \multicolumn{4}{|l|}{ Age group } \\
\hline$<50$ & Reference & & \\
\hline$\geq 50$ & 4.3 & $<0.001$ & $2.6-7.1$ \\
\hline \multicolumn{4}{|l|}{ Sex } \\
\hline Male & Reference & & \\
\hline Female & 1.8 & 0.005 & $1.2-2.8$ \\
\hline \multicolumn{4}{|l|}{ Residence } \\
\hline Rural & Reference & & \\
\hline Urban & 0.9 & 0.603 & $0.5-1.4$ \\
\hline \multicolumn{4}{|c|}{ Marital Status } \\
\hline Married & Reference & & \\
\hline Single & 0.8 & 0.412 & $0.4-1.4$ \\
\hline Separated & 1.8 & 0.462 & $0.4-8.2$ \\
\hline Widowed & 2.5 & 0.006 & $1.3-5.0$ \\
\hline \multicolumn{4}{|c|}{ Any risk factor * } \\
\hline No & Reference & & \\
\hline Yes & 5.3 & $<0.001$ & $2.9-9.9$ \\
\hline
\end{tabular}

Note: *Risk factors included alcohol consumption, smoking, diet, and family history of malignancies. 
Table 3 Clinical Characteristics of CRC at MNRH

\begin{tabular}{|c|c|c|}
\hline Variables & Frequency & Percentage \\
\hline \multicolumn{3}{|l|}{ Site of CRC lesion $(n=132)$} \\
\hline Rectum & 79 & 59.8 \\
\hline Colon & 47 & 35.6 \\
\hline Rectosigmoid & 6 & 4.5 \\
\hline \multicolumn{3}{|l|}{ Staging $(n=44)$} \\
\hline IIA & 5 & 11.4 \\
\hline IIIA & I & 2.3 \\
\hline IIIB & 10 & 22.7 \\
\hline IIIC & 5 & 11.4 \\
\hline IVB & 16 & 36.4 \\
\hline NX & 2 & 4.5 \\
\hline Unclassified $^{\mathrm{a}}$ & 5 & 11.4 \\
\hline \multicolumn{3}{|l|}{ Histology $(n=36)$} \\
\hline Well differentiated adenocarcinoma & 7 & 19.4 \\
\hline Moderately differentiated adenocarcinoma & 8 & 22.2 \\
\hline Poorly differentiated adenocarcinoma & 3 & 8.3 \\
\hline Squamous carcinoma & 2 & 5.6 \\
\hline Villous adenocarcinoma & I & 2.8 \\
\hline Papillary carcinoma & 1 & 2.8 \\
\hline Unclassified $^{\mathrm{a}}$ & 14 & 38.9 \\
\hline
\end{tabular}

Note: ${ }^{\text {a }}$ Commented on the characteristic of the tumor but neither staging nor histology done.

\section{Conclusions}

There is a substantial burden of CRC among patients with lower GIT complaints in Uganda. Females are more affected than males with a median age of 50 years or more. There was no link between sex and the site of primary lesion as previously reported by literature in other parts of the world. Notably, we found a high incidence of CRC among AYAs. Due to a lack of screening programs, patients present with advanced CRC disease which is associated with a poor prognosis. Screening and risk stratification programs need to be introduced to improve clinical outcomes of CRC patients and to enable early identification of those at risk.

\section{Abbreviations}

$\mathrm{CRC}$, Colorectal carcinoma; FAPs, Familial Adenomatous Polyposis syndrome; LMICs, Low-and Middle Income Countries; MHREC, Mulago Hospital Research and Ethics Committee; MNRH, Mulago National Referral Hospital; NCDs, Non-Communicable Diseases; RCR, Retrospective Chart Review.

\section{Acknowledgment}

We extend our sincere thanks to Prof Moses Galukande for his support throughout the ideation and conceptualization of this project. We also thank Prof Sarah Kiguli the principal investigator of Health Professional Education Partnership Initiative (HEPI) for continued mentorship and financial support, Ms Evelyn Bakengesa, Ms Regina Namirembe, and Mr Edward Kasumba during the acquisition of funds. We commend the following people who supported us during the data collection process; Phillip Musoke, Brandy Nantaayi, Violah Nakulima, Patrick Nsamba, Richard Beingana, Anthony Kisaakye, Emmanuel Arthur Makai, Babrah Wannyana, Rodney Kato Ndawula, Mr Assay Balite, and Ms Jaliat Kayaga.

\section{Funding}

Research reported in this publication was supported by the Fogarty International Center of the National Institutes of Health, US Department of State's Office of the US Global AIDS Coordinator and Health Diplomacy (S/GAC), and President's Emergency Plan for AIDS Relief (PEPFAR) under Award Number 1R25TW011213. The content is solely the responsibility of the authors and does not necessarily represent the official views of the National Institutes of Health.

\section{Disclosure}

The authors report no conflicts of interest in this work.

\section{References}

1. Sung H, Ferlay J, Siegel RL, et al. Global cancer statistics 2020: GLOBOCAN estimates of incidence and mortality worldwide for 36 cancers in 185 countries. CA Cancer J Clin. 2021;71(3):209-249.

2. GLOBOCAN. GLOBOCAN 2020: new global cancer data. UICC [Internet]. Status update. 2020 [cited August 10, 2021]. Available from: https://www.uicc.org/news/globocan-2020-new-global-cancerdata. Accessed September 25, 2021.

3. Graham A, Davies Adeloye LG, Theodoratou E, Campbell H. Estimating the incidence of colorectal cancer in Sub-Saharan Africa: a systematic analysis. J Glob Health. 2012;2(2). doi:10.7189/jogh.02.020404

4. Bray F, Jemal A, Grey N, Ferlay J, Forman D. Global cancer transitions according to the human development index (2008-2030): a population-based study. Lancet Oncol. 2012;13(8):790-801. doi:10.1016/S1470-2045(12)70211-5

5. Douaiher J, Ravipati A, Grams B, Chowdhury S, Alatise O, Are C. Colorectal cancer-global burden, trends, and geographical variations. J Surg Oncol. 2017;115(5):619-630. doi:10.1002/jso.24578

6. Jemal A, Bray F, Center MM, Ferlay J, Ward E, Forman D. Global cancer statistics. CA Cancer J Clin. 2011;61(2):69-90.

7. Center MM, Jemal A, Smith RA, Ward E. Worldwide variations in colorectal cancer. CA Cancer J Clin. 2009;59(6):366-378.

8. Talibov M, Sormunen J, Hansen J, et al. Benzene exposure at workplace and risk of colorectal cancer in four Nordic countries. Cancer Epidemiol. 2018;55:156-161.

9. Soliman AS, Smith MA, Cooper SP, et al. Serum organochlorine pesticide levels in patients with colorectal cancer in Egypt. Arch Environ Health. 1997;52(6):409-415. doi:10.1080/00039899709602 219 
10. Spiegelman D, Wegman DH. Occupation-related risks for colorectal cancer. J Natl Cancer Inst. 1985;75(5):813-821. doi:10.1093/jnci/ 75.5.813

11. Kwak K, Paek D, Zoh KE. Exposure to asbestos and the risk of colorectal cancer mortality: a systematic review and meta-analysis. Occup Environ Med. 2019;76(11):861-871. doi:10.1136/oemed-2019-105735

12. Kanthan R, Senger JL, Kanthan SC. Molecular events in primary and metastatic colorectal carcinoma: a review. Patholog Res Int. 2012;2012. doi:10.1155/2012/597497

13. Armaghany T, Wilson JD, Chu Q, Mills G. Genetic alterations in colorectal cancer. Gastrointest Cancer Res. 2012;5(1):19.

14. Testa U, Pelosi E, Castelli G. Colorectal cancer: genetic abnormalities, tumor progression, tumor heterogeneity, clonal evolution and tumor-initiating cells. Med Sci. 2018;6(2):31. doi:10.3390/ medsci6020031

15. Ewing I, Hurley JJ, Josephides E, Millar A. The molecular genetics of colorectal cancer. Frontline Gastroenterol. 2014;5(1):26-30. doi:10.1136/flgastro-2013-100329

16. Li X, Zhou Y, Luo Z, et al. The impact of screening on the survival of colorectal cancer in Shanghai, China: a population based study. BMC Public Health. 2019;19(1):1. doi:10.1186/s12889-019-7318-8

17. Brenner H, Jansen L, Ulrich A, Chang-Claude J, Hoffmeister M. Survival of patients with symptom- and screening-detected colorectal cancer. Oncotarget. 2016;7(28):44695. doi:10.18632/oncotarget.9412

18. Lc C, Jm M, Mi B, Pm H. The rising incidence of younger patients with colorectal cancer: questions about screening, biology, and treatment. Curr Treat Options Oncol. 2017;18(4). doi:10.1007/ s11864-017-0463-3

19. Siegel RL, Miller KD, Sauer AG, et al. Colorectal cancer statistics, 2020. CA Cancer J Clin. 2020;70(3):145-164.

20. Ouakrim DA, Pizot C, Boniol M, et al. Trends in colorectal cancer mortality in Europe: retrospective analysis of the WHO mortality database. BMJ. 2015;351:h4970.

21. Wismayer R. Colorectal adenocarcinoma in East Africa: a narrative literature review. J Adv Med Med Res. 2020;32(6):1-11.

22. Luzzati T, Parenti A, Rughi T. Economic growth and cancer incidence. Ecol Econ. 2018;146:381-396. doi:10.1016/j.ecolecon. 2017.11.031

23. Favoriti P, Carbone G, Greco M, Pirozzi F, Pirozzi REM, Corcione F. Worldwide burden of colorectal cancer: a review. Updates Surg. 2016;68(1):7-11. doi:10.1007/s13304-016-0359-y

24. Miranda JJ, Kinra S, Casas JP, Davey smith G, Ebrahim S. Noncommunicable diseases in low- and middle-income countries: context, determinants and health policy. Trop Med Int Health. 2008;13 (10):1225-1234. doi:10.1111/j.1365-3156.2008.02116.x

25. Nyirenda MJ. Non-communicable diseases in sub-Saharan Africa: understanding the drivers of the epidemic to inform intervention strategies. Int Health. 2016;8(3):157-158. doi:10.1093/inthealth/ihw021

26. Bukirwa $P$, Wabinga $H$, Nambooze $S$, et al. Trends in the incidence of cancer in Kampala, Uganda, 1991 to 2015. Int J Cancer. 2021;148 (9):2129-2138. doi:10.1002/ijc.33373

27. Colorectal Cancer: Risk Factors and Prevention [webpage on the Internet]. Alexandria, VA: Cancer.Net; 2021. Available from: https://www.cancer.net/cancer-types/colorectal-cancer/risk-factorsand-prevention. Accessed September 29, 2021.

28. Wong MCS, Ding H, Wang J, Chan PSF, Huang J. Prevalence and risk factors of colorectal cancer in Asia. Intest Res. 2019;17 (3):317-329. doi:10.5217/ir.2019.00021

29. Abualkhair WH, Zhou M, Ahnen D, Yu Q, Wu X-C, Karlitz JJ. Trends in incidence of early-onset colorectal cancer in the United States among those approaching screening age. JAMA Netw Open. 2020;3 (1):e1920407-e1920407. doi:10.1001/jamanetworkopen.2019.20407

30. Virostko J, Capasso A, Yankeelov TE, Goodgame B. Recent trends in the age at diagnosis of colorectal cancer in the US national cancer data base, 2004-2015. Cancer. 2019;125(21):3828-3835. doi:10.10 $02 /$ cncr.32347
31. Parker RK, Ranketi SS, McNelly C, et al. Colorectal cancer is increasing in rural Kenya: challenges and perspectives. Gastrointest Endosc. 2019;89(6):1234-1237. doi:10.1016/j.gie.2018.12.003

32. Medhin LB, Achila OO, Abrham AT, et al. Incidence of colorectal cancer in Eritrea: data from the national health laboratory, 20112017. PLoS One. 2019;14(11):e0224045. doi:10.1371/journal.pone. 0224045

33. Asombang AW, Madsen R, Simuyandi M, et al. Descriptive analysis of colorectal cancer in Zambia, Southern Africa using the national cancer disease hospital database. PAMJ. 2018;30:248. doi:10.11604/ pamj.2018.30.248.12464

34. You YN, Lee LD, Deschner BW, Shibata D. Colorectal cancer in the adolescent and young adult population. JCO Oncol Pract. 2020;16 (1):19-27. doi:10.1200/JOP1900153

35. Haggar F, Boushey R. Colorectal cancer epidemiology: incidence, mortality, survival, and risk factors. Clin Colon Rectal Surg. 2009;22 (4):191-197. doi:10.1055/s-0029-1242458

36. Exarchakou A, Donaldson LJ, Girardi F, Coleman MP, Manzoli L. Colorectal cancer incidence among young adults in England: trends by anatomical sub-site and deprivation. PLoS One. 2019;14(12): e0225547. doi:10.1371/journal.pone.0225547

37. Cormedi MCV, Lopes EFDT, Maistro S, Roela RA, Folgueira MAAK. Clinical stage and histological type of the most common carcinomas diagnosed in young adults in a reference cancer hospital. Clinics. 2018;73(Suppl 1). doi:10.6061/clinics/2018/e656s

38. Limaiem F, Azzabi S, Sassi A, Mzabi S, Bouraoui S. Colorectal cancer in young adults: a retrospective study of 32 tunisian patients. Pan Afr Med J. 2018;31:62.

39. Determinants of health seeking behaviour in Uganda - is it just income and user fees that are important? [Internet]; [cited September 11, 2021]. Available from: https://ideas.repec.org/p/ags/ idpmde/30553.html. Accessed September 25, 2021.

40. Motsuku L, Chen WC, Muchengeti MM, et al. Colorectal cancer incidence and mortality trends by sex and population group in South Africa: 2002-2014. BMC Cancer. 2021;21(1). doi:10.1186/ s12885-021-07853-1

41. Kehm RD, Yang W, Tehranifar P, Terry MB. 40 years of change in age- and stage-specific cancer incidence rates in US women and men. JNCI Cancer Spectr. 2019;3(3). doi:10.1093/jncics/pkz038

42. El-Haddad B, Dong F, Kallail KJ, Hines RB, Ablah E. Association of marital status and colorectal cancer screening participation in the USA. Colorectal Dis. 2015;17(5):O108-O114. doi:10.1111/codi.12 926

43. Wang X, Cao W, Zheng C, Hu W, Liu C. Marital status and survival in patients with rectal cancer: an analysis of the Surveillance, Epidemiology and End Results (SEER) database. Cancer Epidemiol. 2018;54:119-124. doi:10.1016/j.canep.2018.04.007

44. Saravi BM, Asgari Z, Siamian H, et al. Documentation of medical records in hospitals of Mazandaran university of medical sciences in 2014: a Quantitative Study. Acta Inform Med. 2016;24(3):202. doi:10.5455/aim.2016.24.202-206

45. Abernethy AP, Herndon JE, Wheeler JL, Rowe K, Marcello J, Patwardhan M. Poor documentation prevents adequate assessment of quality metrics in colorectal cancer. J Oncol Pract. 2009;5 (4):167-174. doi:10.1200/JOP.0942003

46. Saadati HM, Okhovat B, Khodamoradi F. Incidence and risk factors of colorectal cancer in the Iranian population: a systematic review. $J$ Gastrointest Cancer. 2021;52(2):414-421. doi:10.1007/s12029020-00574-x

47. Hamdi Y, Abdeljaoued-Tej I, Zatchi AA, et al. Cancer in Africa: the untold story. Front Oncol. 2021;11. doi:10.3389/fonc.2021.650117

48. Sawicki T, Ruszkowska M, Danielewicz A, Niedźwiedzka E, Arłukowicz T, Przybyłowicz KE. A review of colorectal cancer in terms of epidemiology, risk factors, development, symptoms and diagnosis. Cancers. 2021;13(9):9. doi:10.3390/cancers13092025 
49. Chiavarini M, Bertarelli G, Minelli L, Fabiani R. Dietary intake of meat cooking-related mutagens (HCAs) and risk of colorectal adenoma and cancer: a systematic review and meta-analysis. Nutrients. 2017;9(5):514. doi:10.3390/nu9050514

50. Hodge AM, Williamson EJ, Bassett JK, Macinnis RJ, Giles GG, English DR. Dietary and biomarker estimates of fatty acids and risk of colorectal cancer. Int $J$ Cancer. 2015;137(5):1224-1234. doi:10.1002/ijc.29479

51. Aglago EK, Murphy N, Huybrechts I, et al. Dietary intake and plasma phospholipid concentrations of saturated, monounsaturated and Trans Fatty Acids And colorectal cancer risk in the European prospective investigation into cancer and nutrition cohort. Int $J$ Cancer. 2021;149(4):865-882. doi:10.1002/ijc. 33615
52. Dijxhoorn D, Boutall A, Mulder C, et al. Colorectal cancer in patients from Uganda: a histopathological study. East Cent Afr J Surg. 2014;19(1):112-119.

53. Picard E, Verschoor CP, Ma GW, Pawelec G. Relationships between immune landscapes, genetic subtypes and responses to immunotherapy in colorectal cancer. Front Immunol. 2020;11. doi:10.3389/ fimmu.2020.00369

54. Mojarad EN, Kuppen PJK, Aghdaei HA, Zali MR. The CpG island methylator phenotype (CIMP) in colorectal cancer. Gastroenterol Hepatol Bed Bench. 2013;6:120.

\section{Publish your work in this journal}

Cancer Management and Research is an international, peer-reviewed open access journal focusing on cancer research and the optimal use of preventative and integrated treatment interventions to achieve improved outcomes, enhanced survival and quality of life for the cancer patient.
The manuscript management system is completely online and includes a very quick and fair peer-review system, which is all easy to use. Visit http://www.dovepress.com/testimonials.php to read real quotes from published authors. 